\title{
VEINTICINCO AÑOS DE PARIDAD POLÍTICA HOMBRE-MUJER
}

\author{
MATILDE GURRERA
}

Profesora Titular de Derecho Constitucional

Universidad Autónoma de Madrid 
* 


\title{
VEINTICINCO AÑOS DE PARIDAD POLÍTICA HOMBRE-MUJER
}

\author{
POR \\ MATILDE GURRERA \\ Profesora Titular de Derecho Constitucional \\ Universidad Autónoma de Madrid
}

La celebración de los 25 primeros años de nuestra Constitución actual, marca un punto de especial significación en todos los ámbitos, en la vida social, política e institucional, pero desde una perspectiva de género el salto ha sido extraordinario, pues ha permitido que las mujeres españolas vayan saliendo paulatinamente de las situaciones de dependencia y discriminación de siglos, para encaminarse hacia la igualdad no sólo de oportunidades, sino también de resultados.

El principio de no discriminación por razón de sexo enunciado en el art. ${ }^{\circ} 14$ de la Constitución rompe, al menos formalmente, con esta desigualdad tan anclada en la sociedad, y debe ponerse en relación con el mandato a los poderes públicos contenido en el art. ${ }^{\circ} 9.2$ que les obliga a remover los obstáculos y promover las condiciones para que la libertad y la igualdad de los individuos y los grupos sean reales y efectivas... y facilitar la participación de todos los ciudadanos en la vida política..., situándose a su vez dentro del contexto del Estado social y democrático de Derecho que propugna el art. ${ }^{\circ} 1.1$. $Y$ de esta relación entre igualdad formal e igualdad material, podemos extraer que grado de desigualdad es jurídicamente admisible, pues no puede considerarse discriminatoria la actuación de los poderes públicos encaminada a favorecer a aquellos colectivos históricamente marginados. 
Así el art. ${ }^{\circ} 14$ no prohíbe las medidas de acción positiva, antes al contrario, los poderes públicos están obligados a establecer diferenciaciones cuando la igualdad real y efectiva asi lo exija. El principio de igualdad formal permite tratos desiguales siempre que estén fundamentados en una base objetiva y razonable, en consecuencia, los poderes públicos deben tratar por igual a todos los ciudadanos, pero pueden tratar de forma desigual situaciones distintas, a fin de compensar aquellas situaciones de desigualdad sustancial.

NuestroTribunal Constitucional así lo ha entendido a partir de la Sentencia $128 / 87$ primera que admite medidas positivas para favorecer y compensar a las mujeres en el ámbito laboral, estableciendo para ellas un trato compensatorio más favorable, que en ningún caso puede ser considerado contrario al principio de igualdad, sino más bien integrado en el principio de igualdad material consagrado en el art. ${ }^{\circ}$ 9.2, siempre que se respete el principio de proporcionalidad. Así entiende el Alto tribunal que "La actuación de los poderes públicos para remediar la situación de determinados grupos sociales definidos entre otras características por el sexo, no puede considerarse vulneradora del principio de igualdad, aun cuando establezca para ellos un trato más favorable" (STC 128/87). A partir de esta Sentencia, la labor interpretativa llevada a cabo en estos años por el Tribunal Constitucional irá matizando, evolucionando paulatinamente y distinguiendo entre el principio de igualdad en el contenido de la norma, del principio de no discriminación por razón de sexo.

Pero si bien toda esta evolución ha sido positiva, no podemos caer en un falso triunfalismo, hay muchos aspectos en los que queda mucho por hacer, uno de ellos es el relativo a la escasa participación femenina en el ámbito político.

Si bien hoy en día está ampliamente aceptada la importancia de una representación equilibrada de mujeres y hombres en los centros de representación política, pasando a ser el discurso "políticamente correcto" que casi nadie se atreve ya públicamente a contradecir, aunque haya ciudadanos que no crean en él, lo cierto es que la presencia de mujeres en los órganos de decisión política es aún escasa. Esta situación implica un déficit democrático que debe superarse si queremos avanzar por el camino de la profundización democrática.

La ciudadanía se expresa participando y la participación activa es el mejor exponente de la democracia. La democracia paritaria es desde el punto de vista político tan importante como en su día fue la lucha por la obtención del derecho al sufragio activo femenino, derecho que en países como Alemania o Gran Bretaña se alcanzó en 1919, 
en España gracias a la Constitución republicana de 1931, en Francia en 1945 , etc. O sea que el derecho al voto de las mujeres no se conseguirá hasta después de conquistado el sufragio universal (contemplado como universo exclusivamente masculino).

El derecho a la participación política se encuentra regulado en el art. $^{\circ} 23$ de la Constitución, reconociendo tanto el sufragio activo, como el derecho de todos los ciudadanos a acceder en condiciones de igualdad a las funciones y cargos públicos con los requisitos que señalen las leyes. Se trata de un derecho de configuración legal, pero basado en el principio de igualdad como límite para el legislador.

Para favorecer la participación política de las mujeres han surgido un conjunto de medidas de acción positiva, entre otras las llamadas "cuotas" como medidas temporales para corregir una situación de hecho, agilizar el acceso femenino a los órganos de representación y poder llegar así a una situación de paridad, o sea de reparto equilibrado de poderes públicos entre hombres y mujeres.

Desde que 1992 en la declaración suscrita en Atenas en la celebración de "La Primera Cumbre Europea de mujeres en el poder", se acuñó el término "democracia paritaria" para indicar que la participación política de mujeres y hombres en puestos de representación política no fuera superior a un $60 \%$ ni inferior a un $40 \%$, nos encaminamos hacia la superación del sistema de cuotas, buscando medidas de reparto más equilibrado, para lograr en definitiva un proyecto integrador en donde se rompan los roles de género, para que éste deje de determinar espacios concretos, para dar el paso hacia responsabilidades compartidas en todos los ámbitos y conseguir un verdadero derecho de ciudadanía.

Esta preocupación por la escasa participación de las mujeres en los poderes públicos se ha puesto de relieve desde varias instituciones internacionales, así el Consejo de Europa en 1995 estableció la necesidad de que la participación de cada sexo en los órganos de decisión debía apoyarse en la paridad, en la Unión Europea las ministras de los Estados miembros proclamaron en 1996 la necesidad de efectuar un reparto equilibrado de poder entre hombres y mujeres, o la cuarta conferencia mundial de la Organización de las Naciones Unidas celebrada en Pekín en la que los gobiernos se comprometieron a tomar medidas a fin de conseguir el establecimiento de una democracia paritaria. Alguna de estas iniciativas destinadas a lograrla fueron adoptadas en países como Suecia o Noruega, en Bélgica gracias a una ley nacional que prohíbe que el número de candidatos electorales del mismo sexo supere dos tercios del total que representa y en Francia don- 
de fue declarada inconstitucional una ley en este sentido, aunque posteriormente gracias a la reforma constitucional que establece "La ley favorecerá el igual acceso de hombres y mujeres a los mandatos electorales y a las funciones electivas" se logró establecer la paridad por ley, ley que prevé penalizar financieramente a los partidos políticos en caso de incumplimiento. Asimismo, el nuevo proyecto de Constitución Europea presentada el 20 de junio del presente año 2003 en Salónica dispone (art. ${ }^{\circ} \mathrm{I}$ - 2) que la "no discriminación" es uno de los valores en los que se fundamenta la Unión y en su artículo I - 3 se fija explícitamente entre los objetivos de la Unión «el fomento de la igualdad entre hombres y mujeres".

Sin embargo, hay sectores contrarios al sistema de cuotas por considerar que vulnera el principio de igualdad y por ello es discriminatorio, alegan que puede resultar vejatorio para una mujer ser elegida sólo como "mujer florero" o "mujer cuota" y no por razones de talento, capacidad y mérito, entienden que el establecimiento de un sistema de cuotas femeninas supone que todas las mujeres son seleccionadas únicamente por ser mujeres, sin atribuírseles ninguna capacitación, no obstante, cuando en las listas electorales se seleccionan hombres se sobreentiende que es siempre por sus méritos, y ni siquiera se intenta averiguar si los tienen o simplemente acceden por estar dentro del núcleo de los más allegados a quien elabora las listas, que casi seguro que es también varón. Por todo ello, creo que esta argumentación en contra del sistema de cuotas simplemente esconde la misma voluntad de exclusión aunque de forma algo más sutil.

Algunos autores alegan que el sistema de cuotas vulnera la teoría clásica de la representación, pues al ser el cuerpo electoral indivisible, no puede segregarse entre hombres y mujeres, porque los representantes lo son de todos los ciudadanos y no de grupos sexuados. Sin embargo no debemos confundir el derecho al sufragio pasivo con la representación. Está claro que los elegidos, independientemente de si son hombres o mujeres, representan a todos los ciudadanos y que los votantes no están obligados a votar sólo y exclusivamente a los candidatos de su mismo sexo, sino a quién consideren que mejor les representa según sus intereses, que pueden ser ideológicos, económicos, sexuales, o cualesquiera, pues las mujeres también pueden representar a hombres, de no ser así, deberíamos pensar que hoy en día la mayoría de mujeres no están representadas, puesto que los hombres ocupan una cuota del $80 \%$ en el Parlamento. Queda claro que este no es el problema. 
El sistema de cuotas puede plantearse en distintos momentos y por distintos medios. Pueden establecerlas los partidos políticos internamente en sus estatutos. Puede contemplarse en la Ley Electoral o bien puede exigirse constitucionalmente mediante reforma previa.

En algunos paises se han fijado con éxito y en otros fueron rechazadas por los tribunales de justicia, e incluso en algunos países los cambios legislativos en este sentido se declararon inconstitucionales, al interpretar que se estaba vulnerando el principio de igualdad ante la ley, así ocurrió en Francia en 1982 aunque finalmente se logró gracias a una reforma constitucional como ya hemos comentado y en Italia en 1995.

En nuestro país existen sistemas de cuotas voluntarias en varios partidos sobre todo para elaborar las listas electorales, habiendo obtenido puestos representativos mayor número de mujeres, y aquellos que no han impuesto este sistema alegando no estar de acuerdo con el mismo han intentado incrementar de otra manera la presencia de mujeres, quizá para poner de manifiesto que el sistema de cuotas no era efectivo, queriendo demostrar que sin adoptarlo habian conseguido mayor número de mujeres en puestos de responsabilidad, no podemos olvidar que lo más importante es haber conseguido que el tema de la democracia paritaria esté tan en voga que se incluya dentro de los programas electorales, o sea que tanto sus partidarios como sus detractores finalmente al querer demostrar que ellos son quienes tienen la razón, han incluido más mujeres en puestos de responsabilidad, o sea que el resultado práctico ha sido efectivo.

Ahora bien, para garantizar la democracia paritaria o sea que todos los partidos concurrieran a las elecciones con determinado porcentaje de mujeres, o con un cierto equilibrio entre mujeres y hombres, debería legislarse al efecto.

En España no se ha intentado por ahora esta solución y por tanto no sabemos cuál sería en su caso el pronunciamiento del Tribunal Constitucional, aunque todo apunta a que declararía su constitucionalidad, porque como señalábamos al principio, nuestra Constitución si admite las acciones positivas en general, y en particular el Tribunal ha aceptado el sistema de cuotas para minusválidos en la reserva porcentual de plazas en una oferta de empleo público, que si bien no es el mismo supuesto, al menos manifiesta que las medidas de acción positiva si tienen cabida dentro de nuestro marco constitucional, siendo desde nuestro punto de vista una cuestión de justicia establecerlas hasta lograr un mayor equilibrio. 


\section{REFERENCIAS BIBLIOGRÁFICAS}

REY, Fernando, El derecho fundamental a no ser discriminado por razón de sexo, Ed. McGraw-Hill, 1995.

Mujer y Constitución en España, Ed. Centro de Estudios Políticos y Constitucionales, Madrid, 2000.

CELEM (Paloma Saavedra, dir.), Hacia una Democracia Paritaria. Análisis y Revisión de las Leyes Electorales vigentes, 1999.

Gude FernÁndez, Ana, «El principio de igualdad: a propósito de las discriminaciones y acciones positivas (una visión europea)", en Parlamento y Constitución, n. ${ }^{\circ}$ 5, Anuario 2001. 